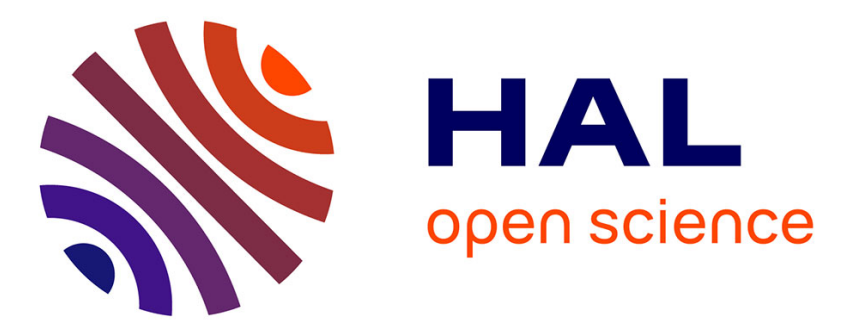

\title{
On the variety and formation sequence of second-phase particles in nickel-based superalloys fabricated by laser powder bed fusion
}

\author{
A. Després, C. Mayer, G. Martin, M. Veron, E.F. Rauch, Matthieu Bugnet, \\ J.-J. Blandin, G. Renou, C. Tassin, Patricia Donnadieu
}

\section{To cite this version:}

A. Després, C. Mayer, G. Martin, M. Veron, E.F. Rauch, et al.. On the variety and formation sequence of second-phase particles in nickel-based superalloys fabricated by laser powder bed fusion. Materialia, 2021, 15, pp.101037. 10.1016/j.mtla.2021.101037 . hal-03367574

\section{HAL Id: hal-03367574 \\ https://hal.science/hal-03367574}

Submitted on 18 Oct 2021

HAL is a multi-disciplinary open access archive for the deposit and dissemination of scientific research documents, whether they are published or not. The documents may come from teaching and research institutions in France or abroad, or from public or private research centers.
L'archive ouverte pluridisciplinaire HAL, est destinée au dépôt et à la diffusion de documents scientifiques de niveau recherche, publiés ou non, émanant des établissements d'enseignement et de recherche français ou étrangers, des laboratoires publics ou privés. 


\title{
On the variety and complexity of second-phase particles in nickel-based superalloys fabricated by laser powder bed fusion
}

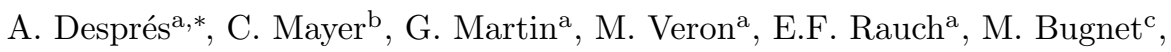

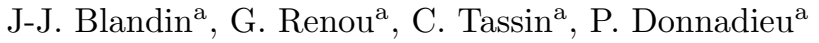 \\ ${ }^{a}$ Univ. Grenoble Alpes, CNRS, Grenoble INP, SIMaP, F-38000 Grenoble, France \\ ${ }^{b}$ Aubert et Duval \\ ${ }^{c}$ Université de Lyon, INSA Lyon, UCBL Lyon 1, MATEIS, UMR 5510 CNRS, 69621 \\ Villeurbanne Cedex, France
}

\begin{abstract}
We examine by transmission electron microscopy the precipitation state in the as-built microstructure of a nickel-based superalloy fabricated by laser powder bed fusion. Most observations are carried out on carbon extraction replica to isolate the different signals of the precipitates from those of the matrix. Composition maps measured by energy dispersive X-ray spectrometry are compared to phase and orientation maps obtained on the same precipitates by automated crystal orientation mapping. The composition analyses are completed by electron energy-loss spectrometry measurements made on thin foils. A large variety of nano-particles is found: $(\mathrm{Ti}, \mathrm{Nb})(\mathrm{C}, \mathrm{N})$ carbonitrides, $(\delta) \mathrm{Al}_{2} \mathrm{O}_{3}$ alumina, $(\mathrm{Cr}, \mathrm{Mo})_{3} \mathrm{~B}_{2}$ and $(\mathrm{Cr}, \mathrm{Mo})_{5} \mathrm{~B}_{3}$ borides, and the intermetallic phase $\mathrm{Ni}_{7} \mathrm{Zr}_{2}$. The precipitation state is also complex in terms of its structure: carbonitrides can present a core-shell structure of composition and are frequently twinned, alumina particles serve as nucleation sites for carbide agregates, and several crystallographic phases of borides may coexist next to each other. These observations allow one to retrace the genesis of the microstructure during fabrication and to discuss the precipitation mechanisms under the extreme processing conditions associated with laser powder bed fusion.
\end{abstract}

\footnotetext{
${ }^{*}$ Corresponding Author,

Email address: arthur.despres@grenoble-inp.fr (A. Després)
}

Preprint submitted to Elsevier

September 14, 2020 
Keywords: nickel-based superalloys, precipitation, additive manufacturing, TEM

\section{Introduction}

The fabrication of nickel-based superalloy components by additive manufacturing processes faces a number of challenges of metallurgical origin which are hardly overcame by process optimization. We take in this paper the laser powder bed fusion (L-PBF) ${ }^{1}$ process as a typical illustration of these challenges. The fast cooling rates inherent to the process $\left(\sim 10^{6} \mathrm{Ks}^{-1}\right)$ induce complex microstructures with small dendrite size, microsegregations and precipitation of nano-sized second-phase particles 1, 2, 3, 4, 5, 6. The existence of thermal stresses acting on the residual liquid films during the last stage of solidification may further lead to the formation of hot cracks at high-angle grain boundaries, which deteriorates the mechanical properties of the component [6, 7, 8]. The hot cracking susceptibility of an alloy depending, in first approximation, on the solidification path, the microsegregations and the precipitation state, characterizing the as-built microstructures is of great importance to understand and control this phenomenon.

In this context, the precipitation state is of high interest as it provides a post-mortem testimony of the microstructure formation. For alloys frequently investigated, e.g. the 718 and 738 grades, previous works have reported evidences of a wide range of precipitates: $\gamma^{\prime}$ phase [5], $\delta$ phase 4], Laves phases [9], carbides [10, 6] and borides [10]. One ought to carefully interpret those reports however, since many potential phases have a similar composition, e.g. $\gamma^{\prime \prime}$ and $\delta$ phases differ only by their crystallography [11, or similar lattice parameters, e.g. the different borides. Most works presenting only the crystallography [5] or the composition [4, 6, 9, 10, of a few selected particles, the current litterature does not allow one to establish a comprehensive picture of the precipitation

\footnotetext{
${ }^{1}$ Also sometimes referred to as the commercial name selective laser melting (SLM).
} 
state in these microstructures.

Due to their small size and fraction, precipitates in as-built microstructures must be probed with nanometric-resolution equipments. Accurate ways to identify second-phase particles are to analyze selected area diffraction patterns in the TEM [3] or the local stoichiometry using atom probe tomography [6, 10]. These approaches provide however very local characterizations of the particles, which further limits the representativity of the results relative to the whole sample.

This work aims to establish a classification of the types second-phase particles found in the as-built microstructure of a nickel-based superalloy fabricated by L-PBF. To overcome the limitations of the above-mentioned approaches, a multi-modal mapping approach has been implemented in the TEM. The composition of particles was investigated by energy dispersive X-ray spectrometry (EDX) and electron energy-loss spectrometry (EELS) maps, while automated crystal orientation mapping (ACOM) was carried out to identify their crystalline structure. The second-phases were identified by comparing the composition and crystallographic data to tables of candidate phases typically found in nickelbased superalloys. This approach allows the composition and crystallography of a large number of second-phase particles to be scanned at the same time. The results unveil the variety and complexity of the precipitation state in as-built samples, and allow one to retrace the microstructure formation sequence during fabrication.

\section{Methodology}

\subsection{Fabrication and preliminary observations}

A powder batch of AD730 alloy was supplied by Aubert et Duval. For confidentiality reasons, we provide only bounds of composition of the commercial powder in Table 1. Nitrogen and oxygen do not enter in the nominal composition but exist as traces resulting from the powder fabrication process. Two 
independent studies have shown that the oxygen content before fabrication is classically around $0.015 \mathrm{wt} \%[12,13]$.

Table 1: Bounds of composition for commercial AD730, in wt.\%.

\begin{tabular}{cccccccccccccc}
$\mathrm{Ni}$ & $\mathrm{Cr}$ & $\mathrm{Co}$ & $\mathrm{Mo}$ & $\mathrm{W}$ & $\mathrm{Al}$ & $\mathrm{Ti}$ & $\mathrm{Nb}$ & $\mathrm{C}$ & $\mathrm{B}$ & $\mathrm{Fe}$ & $\mathrm{Zr}$ & $\mathrm{N}$ & $\mathrm{O}$ \\
\hline bal. & 14 & 7 & 2 & 1.5 & 1.8 & 2.8 & 0.5 & 0 & 0.003 & 3.6 & 0.01 & tr. & tr. \\
bal. & 17 & 10 & 5 & 3.5 & 2.8 & 4.2 & 2.5 & 0.07 & 0.03 & 7 & 0.06 & tr. & tr.
\end{tabular}

Samples of $10 \mathrm{~mm} \times 13 \mathrm{~mm} \times 100 \mathrm{~mm}$ were fabricated by L-PBF on a EOS M290 machine. The processing parameters were chosen after a parametric study with the aim of minimizing the pore density, and are in the range of those previously reported for fabricating nickel-based superalloy components [3, 6, 8]. A few prelimary observations were carried out by optical microscope and scanning electron microscope to give an overview of the as-built microstructure and compare its state to the classic results from the litterature.

\section{2. $A C O M$ and $E D X$ observations on carbon replica}

Precipitates were extracted on carbon replicas in order to isolate their diffraction and x-ray signals from those of the matrix. The sample preparation follows the procedure of Goodfellow et al. [14. It consists in (i) electropolishing a mechanically polished sample in a solution of $10 \%$ phosphoric acid in distilled water, (ii) coating it with a $\sim 20 \mathrm{~nm}$ thick film of amorphous carbon, (iii) removing the film with the precipitates on it by electropolishing the sample in a solution of $20 \%$ perchloric acid in ethanol and (iv) depositing it on copper microgrids. This procedure was choosen as it preserves the intermetallic particles, in particular potential $\gamma^{\prime}$ phase precipitates [14].

The carbon replicas were observed in the TEM using a JEOL $2100 \mathrm{~F}$ at $200 \mathrm{kV}$ accelerating voltage. EDX maps were collected to measure the elemental enrichments at the precipitates. The $\mathrm{K}_{\alpha}$ emission ray was used for detecting all elements except molybdenum, selecting in this later case the $\mathrm{L}_{\beta}$ ray. The light elements, namely boron, carbon, nitrogen, oxygen could not be detected, either due to the absence of a detectable signal (for boron) or to the carbon replica. 
On the same regions of interest, ACOM maps of crystallographic phases and orientations were acquired with the hardware and software toolset ASTAR. The details of this technique are given in ref. [15. A map of selected area diffraction patterns is acquired with a CCD camera located out of the microscope, and the phase and orientation at each position are assigned by comparing its Bragg spot diffraction pattern to simulated patterns of candidate phases and orientations. The simulated pattern having the highest correlation index with the acquired diffraction pattern determines the best solution.

As ACOM only establishes correlations between actual and simulated patterns, a careful preliminary work is required to establish candidate phases. The list shown in Table 2 and used for all subsequent analyses has been established using results from the litterature and insights from thermodynamic calculations using Thermocalc (TCNI9 database). Apart from the $\gamma^{\prime}$ phase, the candidate phases all contains elements that are quasi-insoluble in a nickel matrix according to the Hume-Rothery rule (i.e. boron, carbon, nitrogen, oxygen and zirconium) [16.

\subsection{EELS observations on thin foils}

To provide complementary analyses of the particles composition, thin foils of materials were observed by EELS. The interest of the EELS technique for the present work lies in its ability to detect the light elements. The thin foils were electro-polished in a solution of 5\% perchloric acid in methanol. Acquisitions were performed using a Jeol JEM-ARM200F NeoARM, equipped with a high brightness cold FEG, a Gatan imaging filter Quantum, a last generation ASCOR probe corrector, and operated at $200 \mathrm{kV}$. The elemental maps were acquired using the Spectrum Imaging technique as implemented in the Gatan digital micrograph software. 
Table 2: Candidate phases for identification in ACOM. The lattice parameters of the $\gamma^{\prime}$ phase were measured by X-ray diffraction on a heat treated sample. Small variations of lattice parameters may be reported between different articles, but these have no significant effect on the phase identification. Note that other structures of alumina were ignored as they presented poor correlation indeces with the observed particles.

\begin{tabular}{ccccc} 
Name/stoechiometry & Space group & $a, b, c(\AA)$ & $\alpha, \beta, \gamma\left(^{\circ}\right)$ & Ref. \\
\hline$\gamma^{\prime} / \mathrm{Ni}_{3}(\mathrm{Ti}, \mathrm{Al})$ & $\mathrm{Pm} \overline{3} \mathrm{~m}(221)$ & $3.59,-,-$ & $90,-,-$ & $\mathrm{XRD}$ \\
$(\mathrm{Ti}, \mathrm{Nb})(\mathrm{C}, \mathrm{N})$ & $\mathrm{Fm} \overline{3} \mathrm{~m}(225)$ & $4.36,-,-$ & $90,-,-$ & {$[17]$} \\
$(\mathrm{Cr}, \mathrm{Mo})_{2} \mathrm{~B}$ & $\mathrm{I} 4 / \mathrm{mcm}(140)$ & $5.20,-, 4.30$ & $90,-,-$ & {$[18]$} \\
$(\mathrm{Cr}, \mathrm{Mo})_{3} \mathrm{~B}_{2}$ & $\mathrm{I} 4 / \mathrm{mcm}(140)$ & $5.79,-, 3.06$ & $90,-,-$ & {$[19]$} \\
$(\mathrm{Cr}, \mathrm{Mo})_{5} \mathrm{~B}_{3}$ & $\mathrm{I} 4 / \mathrm{mcm}(140)$ & $5.88,-, 10.10$ & $90,-,-$ & {$[19]$} \\
$\mathrm{Ni}_{7} \mathrm{Zr}_{2}$ & $\mathrm{C} 2 / \mathrm{m}(12)$ & $4.82,8.22,11.13$ & $90,96.7,90$ & {$[17]$} \\
$\mathrm{Ni}_{5} \mathrm{Zr}$ & $\mathrm{F} \overline{4} 3 \mathrm{~m}(216)$ & $6.07,-,-$ & $90,-,-$ & {$[20]$} \\
$(\theta) \mathrm{Al}_{2} \mathrm{O}_{3}$ & $\mathrm{C} 2 / \mathrm{m}(12)$ & $11.79,2.91,5.62$ & $90,103.79,90$ & {$[21]$} \\
$(\delta) \mathrm{Al}_{2} \mathrm{O}_{3}$ & $\mathrm{P} \overline{4} \mathrm{~m} 2(115)$ & $5.59,-, 23.65$ & $90,-,-$ & {$[22]$}
\end{tabular}

\section{Experimental observations}

\subsection{Microstructure overview}

Figure 1 presents an overview of the microstructure at different scales. The optical micrograph in Figure 1a shows that the as-built microstructure presents the general characteristics of L-PBF microstructures of nickel based superalloys. The melt pools generated by the laser scan are about $200 \mu m$ in width. The grains present irregular shapes and grow preferentially by epitaxy through several melt pools in the build direction. The density of the material is above 99,9\%. Figure 1p shows that, at a smaller scale, grains are composed of columnar dendrites and second-phase particles. The dendrites are revealed by lines of microsegregations (in darker grey-level) in the interdendritic regions. Grain boundaries are delimited by dendrites going in different directions. Numerous particles are found near the interdendritic regions and at grain boundaries, which confirms that most of them precipitate near the end of solidification and in close relation with microsegregations. As will be shown below, the grey-level 
of the particles (related to their average atomic number) is far from sufficient to identify their phase.
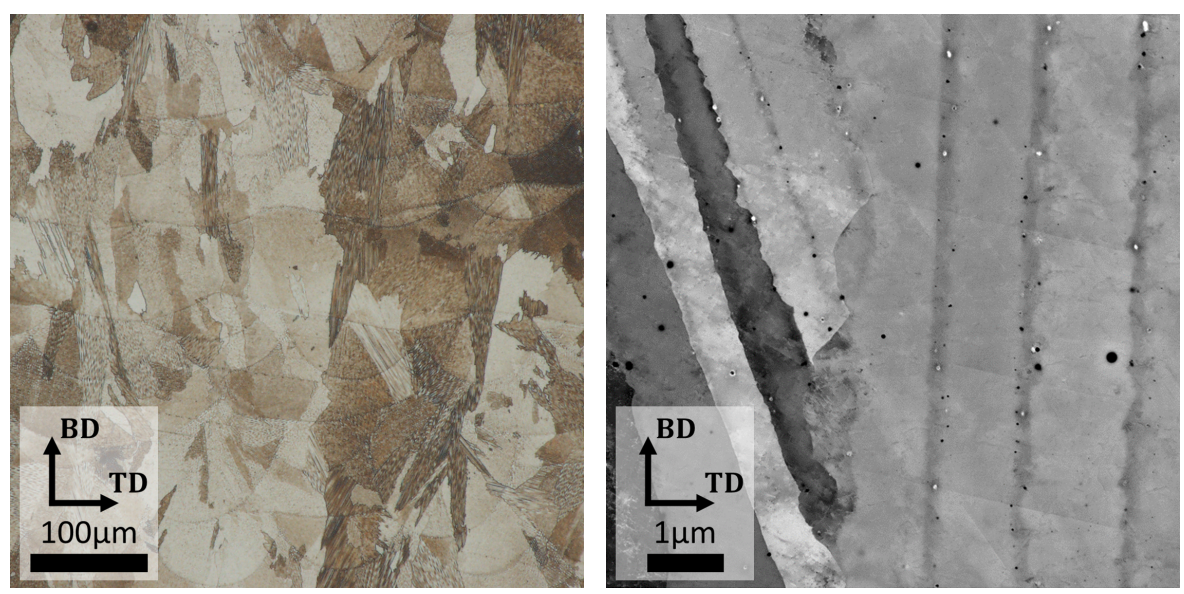

Figure 1: a) Optical micrograph of the as-built microstructure etched in aqua regia. The building direction is denoted $\mathrm{BD}$, and the transverse direction TD. b) Back-scattered electron micrograph taken in the scanning electron microscope. The grey-level contrast between dendrites comes from differences of chemistry, while the contrast between grains comes from crystallography. The saturated grey-level of the particles (either black or white) suggest that their contrast comes from chemistry.

Even from a qualitative point of view, one can sense from Figure $1 \mathrm{~b}$ that the size and fraction of the second-phase particles is too small to perform phaseidentification by conventional X-ray diffraction. This is why TEM observations have been carried out. In the following sections a systematic listing of the types of second-phase particles identified by TEM will be presented. Particular attention will be paid to the particles composition, to their defect structure and to their relationship with other particles. While large areas were scanned, only small exemplary cases will be presented in order to focus this paper on the identification and classification of the second-phase particles. It is also relevant to mention that in this work no $\gamma^{\prime}$ particles have been detected. This absence cannot be ascribed to a dissolution of particles during the carbon replica since 
the procedure was specifically selected to preserve the $\gamma^{\prime}$ phase $2^{2}$

\subsection{Carbonitrides}

About $90 \%$ of the observed particles were $(\mathrm{Ti}, \mathrm{Nb})(\mathrm{C}, \mathrm{N})$ carbonitrides, with a size of the order of $10 \mathrm{~nm}$ to $100 \mathrm{~nm}$ in equivalent diameter. The term carbonitride is used here in a generic sense to characterize particles containing carbon, or nitrogen, or both, and whose crystallographic structure is cubic with a lattice parameter close to $4.36 \AA$ (see Table 2 ). While this type of particle has already been observed in as-built microstructures of nickel-based superalloys [3, 6, 5], several remarkable features are revealed by the present analysis.

One first interesting feature of carbonitrides is their broad composition range. This is illustrated in Figure 2 by two EELS observations. On the one hand, the particle in Figure $2 \mathrm{a}, \mathrm{b}$ is composed of a core of carbon and titanium, and a partial shell of carbon and niobium (note that the residual presence of carbon and niobium at the core is likely an artefact of the 3D geometry of the particle). On the other hand, the particle in Figure 2, d is a pure carbide with a uniform distribution of titanium and niobium. The method to distinguish carbonitrides from pure carbides is based on the electron energy loss spectra and is detailed in Appendix A It will be shown in a subsequent figure that even pure nitrides can be found at the same scale. The existence of core-shell structures with nitrogen at the core and niobium at the shell and the broadness of the stoichioemetry range are also recognized in welds of nickel based superalloys [23. In this case, the particles were about $1 \mu \mathrm{m}$ in equivalent diameter, which indicates that core-shell structures form over a large range of sizes, and by extension, cooling rates.

Figure 3 shows a region of carbon replica containing several carbonitrides. A small boride is also identified in this figure, but a better example will be presented later. On the EDX maps, carbonitride particles exhibit peaks of

\footnotetext{
${ }^{2}$ Note that we confirmed that this procedure preserves the $\gamma^{\prime}$ phase by observing carbon replica made from heat treated samples.
} 

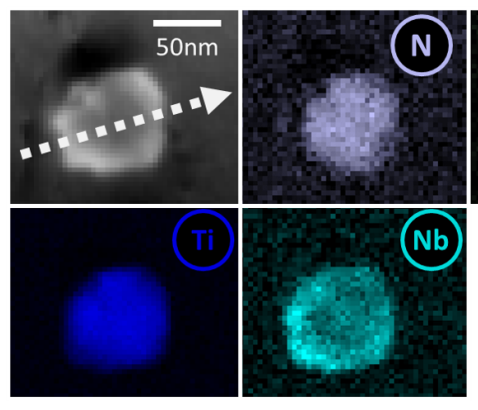

(a)

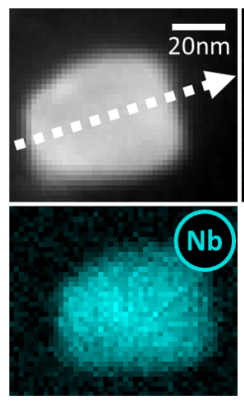

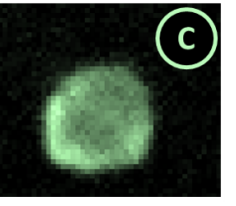
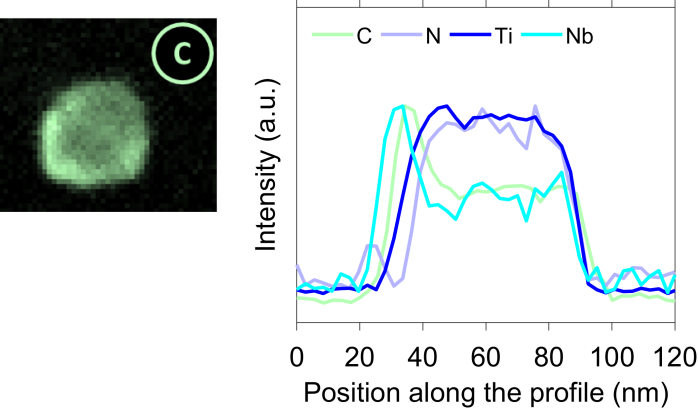

(b)

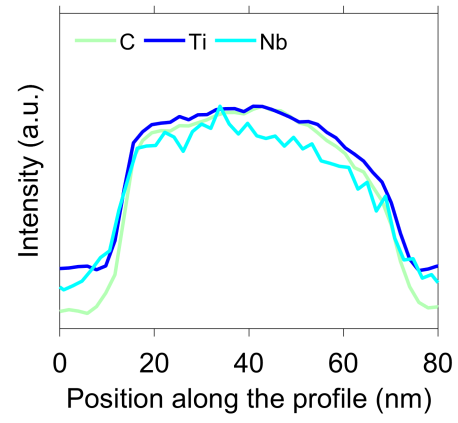

(d)

Figure 2: a,b) EELS maps and intensity profile of a carbonitride with a core-shell structure. c,d) EELS maps and intensity profile of a pure carbide. The maps on the top right of a) and c) are high-angle annular dark field images. Observations are carried out on thin foils. 


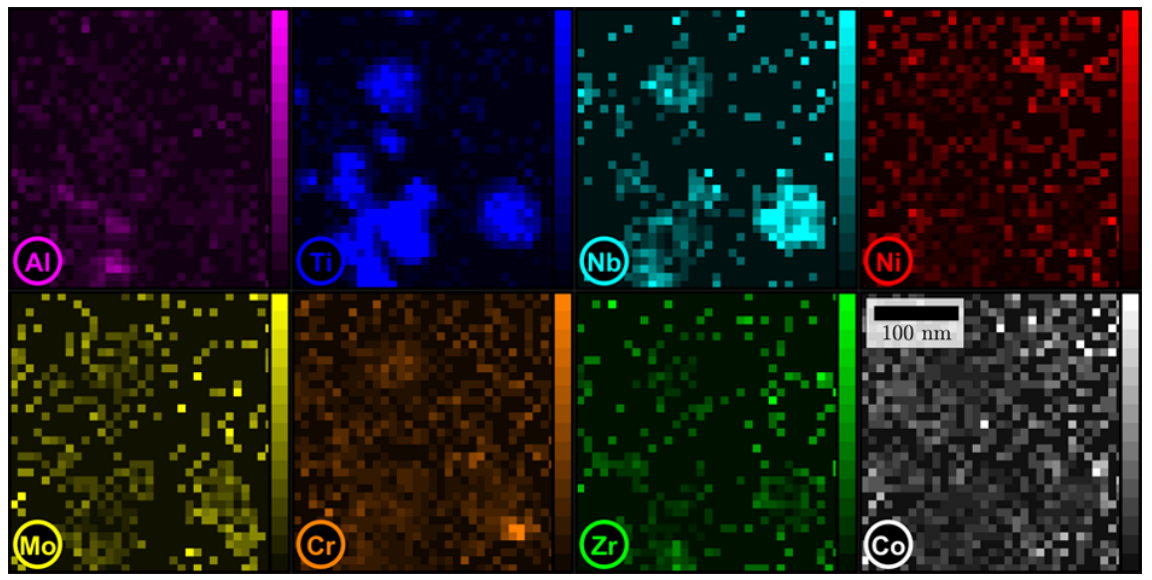

(a)

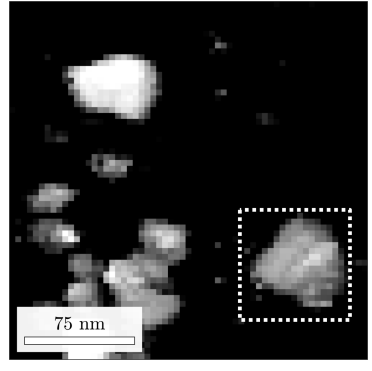

(b)

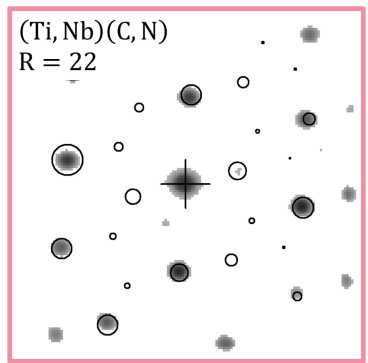

(e)

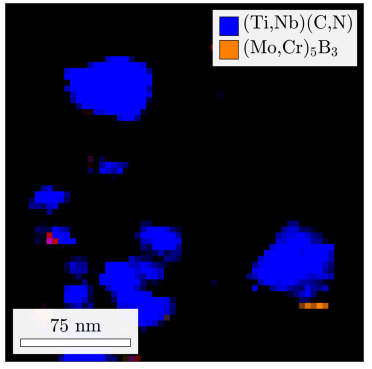

(c)

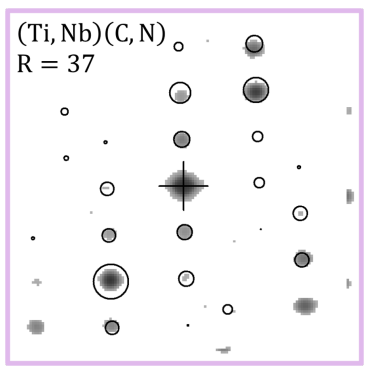

(f)

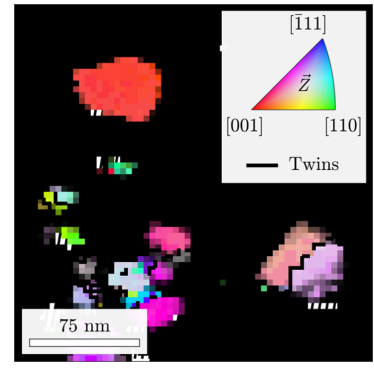

(d)

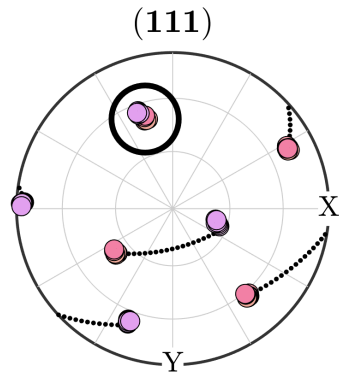

(g)

Figure 3: Region with carbides. a) EDX maps, b) ACOM correlation index map, c) phase+correlation index map and d) IPF+correlation index map. All candidate phases were kept for the indexation by ACOM. e,f) acquired diffraction patterns on the two sides of the twin boundary compared to the simulated patterns (in circles). g) (111) pole figure of the carbide orientations in the white rectangle. The colors follow the IPF key. The $60^{\circ}$ rotation around the shared (111) axis is represented by the black circle and lines. 
titanium and sometimes niobium (Figure 3 a). The location of those peaks matches the identification of the crystallographic structure of carbonitrides by ACOM (Figure 3b-d). The diffraction patterns in Figure 3e,f provide evidence that the structures are well identified. The phase reliability index $R$ overlaid on the patterns is defined as $R=100\left(1-I_{1} / I_{2}\right)$ with $I_{1}$ and $I_{2}$ the correlation indices of the two best solutions. This pararameter is for both patterns above 15 , which is considered sufficient to ascertain that the identified phase is without ambiguity the best solution out of all candidates [15].

A second noticeable feature of carbonitrides is the presence of internal twin boundaries, see for example the particle denoted by the arrow in Figure 3 d. As shown by Figure 3 , the orientations on the two side of the boundary are related by a twin relationship, i.e. a $60^{\circ}$ rotation around a shared $<111>$ axis. It must be emphasized that this is not an isolated case. In Figure $3 \mathrm{~d}$, a significant fraction of the smaller particles exhibit boundaries within $5^{\circ}$ from the theoretical twin relationship (and their orientations are indexed with a similar quality as the larger ones). Looking at the litterature, it appears that twinned carbonitrides do not occur in conventionally cast and wrought superalloy microstructures, but that they have been reported once in a laser remelted single crystal of nickel based superalloy [24]. The origin of these twins will be further discussed later in this paper.

\subsection{Alumina}

Alumina accounts for about $5 \%$ of the particles characterized in this work. Their size ranges approximately from $50 \mathrm{~nm}$ to $150 \mathrm{~nm}$ in equivalent diameter. They are characterized as particles containing aluminium and oxygen and having a tetragonal structure of the $(\delta)$ form (Table 2 ).

Figure 4 shows two alumina particles observed by EELS. The particles are easily identified thanks to their aluminium and oxygen signals. It is noticeable in both Figure 4 and Figure 4 that carbonitride particles are agregated to the alumina. This confirms a recent observation made by EDX on a similar nickelbased superalloy fabricated by L-PBF [13. As for the isolated carbonitrides 
shown in the previous section, the carbonitride agregates have a broad composition range, varying from pure nitrides, in Figure $4 \mathrm{a}, \mathrm{b}$, to true carbonitrides with core-shell structures, in Figure 4e, d.
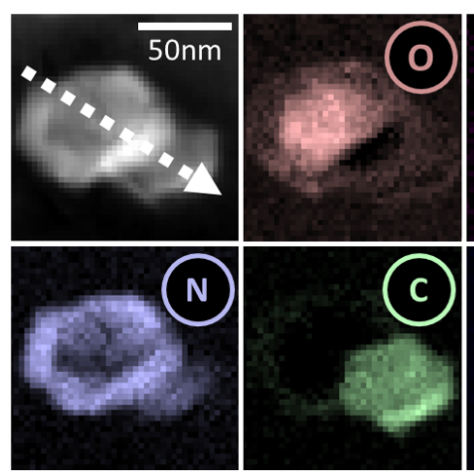

(a)
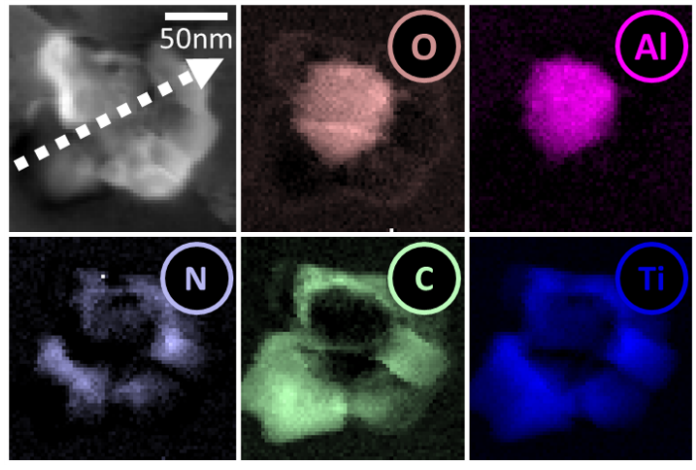

(d)
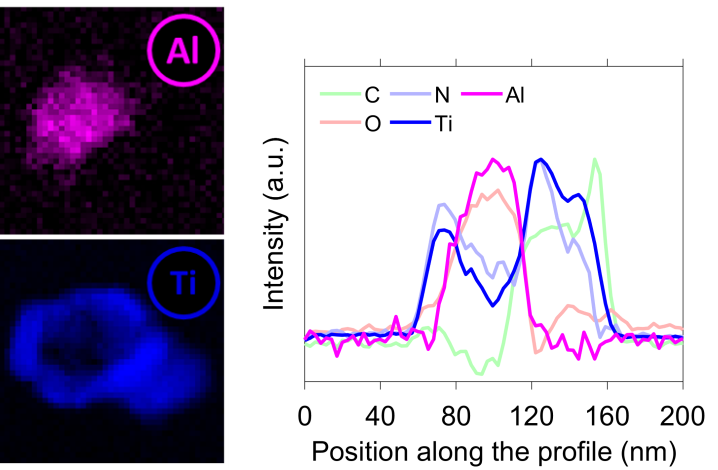

(b)

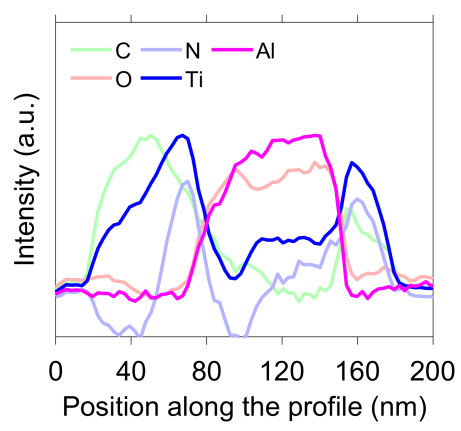

(d)

Figure 4: a,b) EELS maps and intensity profile of an alumina particle surrounded by pure nitrides and a carbonitride. c,d) EELS maps and intensity profile of an alumina particle surrounded by carbonitrides with core-shell structures. The maps on the top right of a) and c) are high-angle annular dark field images. Observations are carried out on thin foils.

In a way similar to the isolated carbonitride particles, Figure 5 shows an example of alumina particle surrounded by carbonitrides as observed on the carbon replica. On the EDX maps and EDX profile, in Figure 5 a and e, the alumina particle is identified thanks to the strong signal of aluminium surrounded 


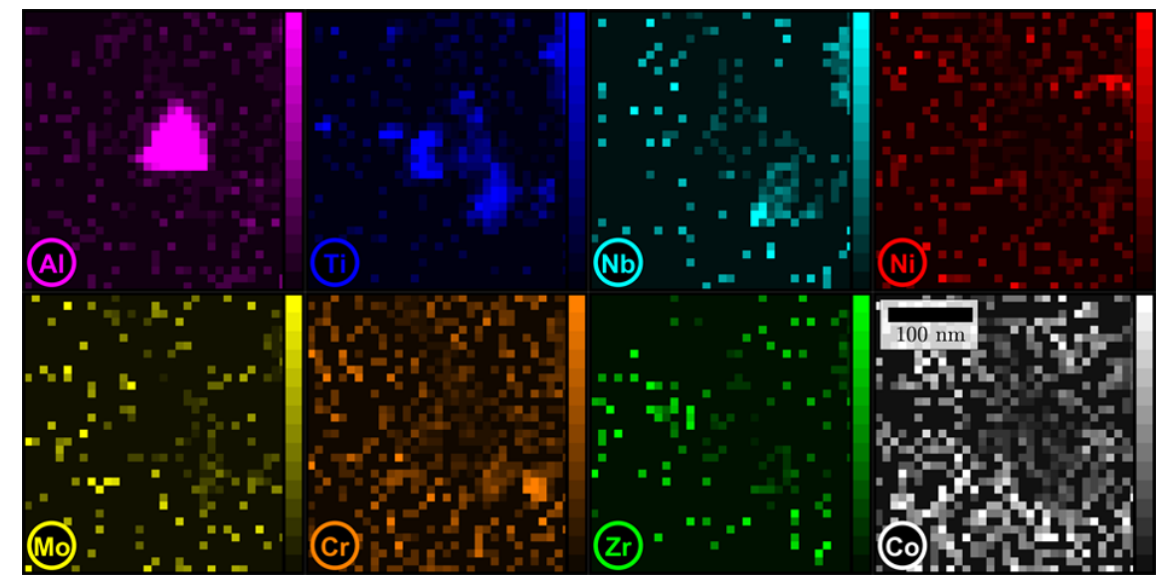

(a)

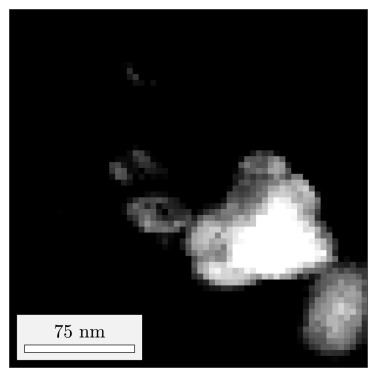

(b)

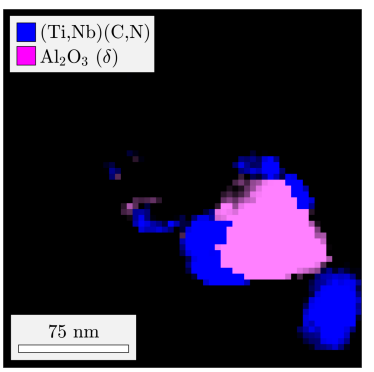

(c)

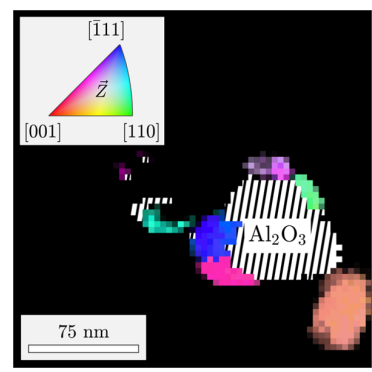

(d)

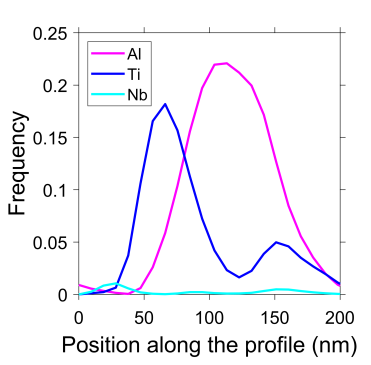

(e)

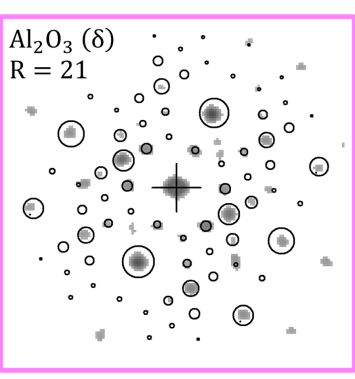

(f)

Figure 5: Region with alumina. a) EDX maps, b) ACOM matching index map, c) phase+matching index map and d) IPF+matching index map for the carbide phase. All candidate phases were kept for the indexation by ACOM. e) EDX profile across the alumina particle. f) acquired diffraction patterns on the alumina particle and its comparison to the simulated pattern. 
by titanium. As shown by Figure 5b-d, the presence of the alumina particle surrounded by carbonitrides is confirmed by the crystallographic information provided by ACOM. Figure 5f shows that the indexation of the diffraction pattern is again excellent. Note that out of the 12 alumina particles investigated, all of them were indexed as $(\delta)$ alumina, while the $(\theta)$ form was systematically the second best solution, but with significantly poorer correlation indeces.

It is also noticeable from Figure $5 \mathrm{~d}$ that the carbonitride agregate on the alumina particle is polycrystalline. As for the isolated carbonitrides, agregated carbonitrides may occasionally exhibit internal twins. It is for this reason more adequate to qualify as agregates the carbonitrides appended to alumina particles, while the term core-shell holds in this work for precipitates of unique crystallography presenting gradients of composition.

\subsection{Borides}

Borides in nickel-based superalloys are composed of boron, chromium and molybdenum [11. The two metallic elements are considered as more or less invertible, and their relative fraction is likely to change as a function of the nominal composition of the alloy. Borides possess a tetragonal structure which has been reported under several forms and associated stoechiometry (see Table 2). In the present work, boride particles have not been detected by EELS due to their low fraction relative to carbides. Their size is in the same range as other particles, they do not seem to develop particular morphological features, and their average atomic number must be close to that of carbonitrides. Therefore they cannot be easily distinguished by conventionnal imaging.

Figure 6 shows an example where a boride particle is located next to a carbide. On the EDX maps and profile, in Figure $6 \mathrm{a}$ and e, the chromium and weak molybdenum peaks denote the position of the boride, while the titanium peak denotes the carbonitride. As shown by the ACOM maps in Figure $6 \mathrm{~b}-\mathrm{c}$, boride particles of the $(\mathrm{Cr}, \mathrm{Mo})_{3} \mathrm{~B}_{2}$ and $(\mathrm{Cr}, \mathrm{Mo})_{5} \mathrm{~B}_{3}$ structure may coexist next to each other (note, again, that the carbonitride in Figure $6 \mathrm{~d}$ is twinned). The diffraction patterns of the two boride phases in Figure 6;, $g$ are well indexed, and their 


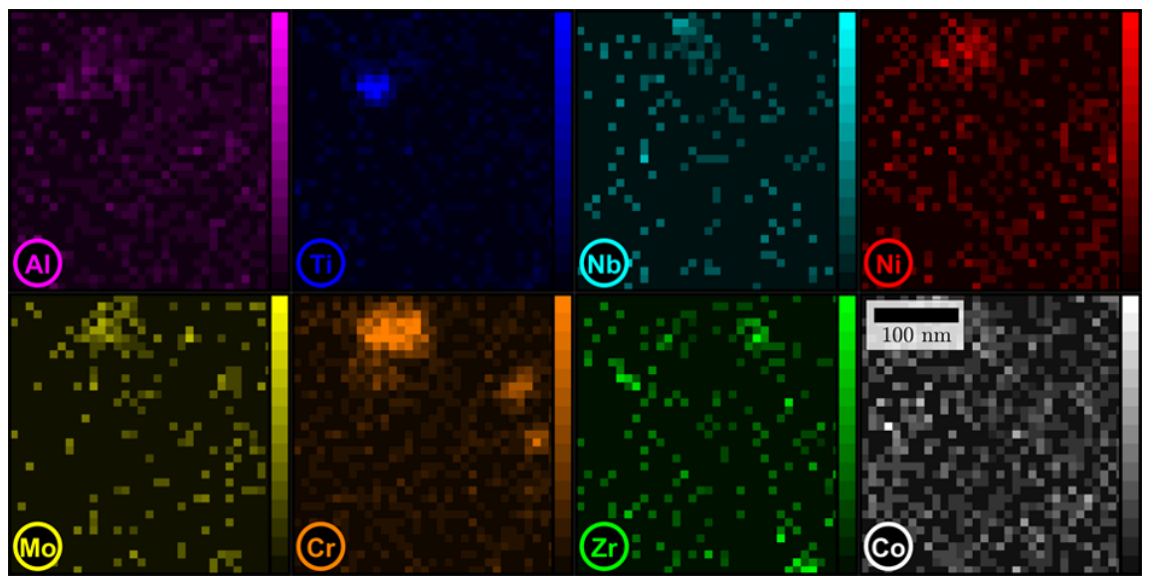

(a)

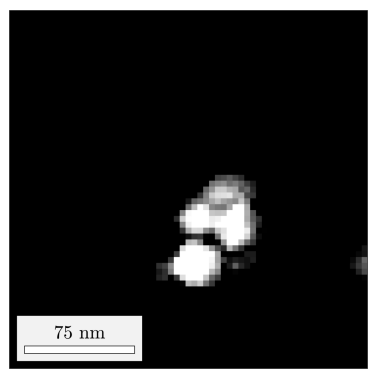

(b)

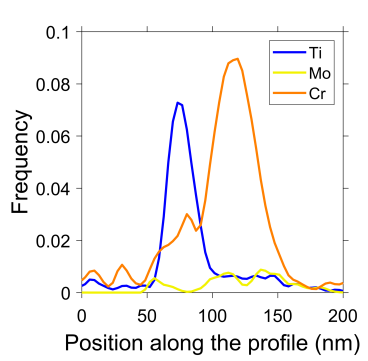

(e)

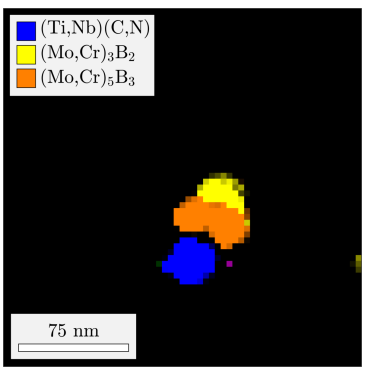

(c)

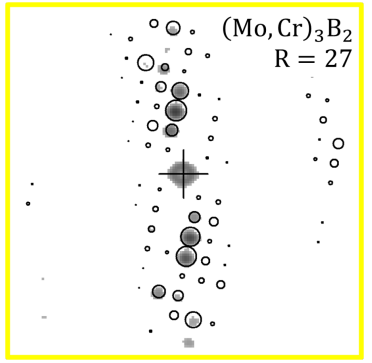

(f)

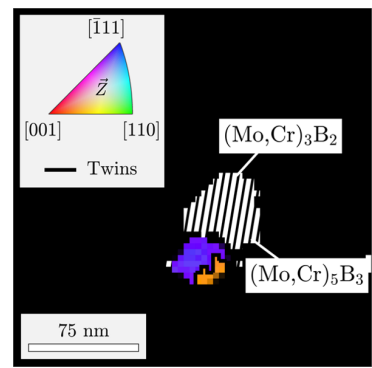

(d)

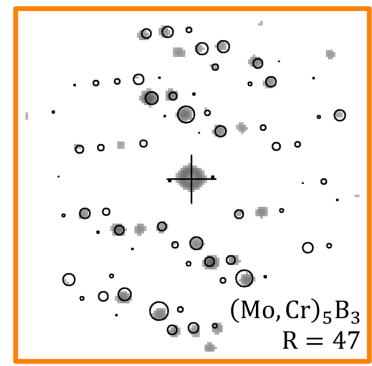

$(\mathrm{g})$

Figure 6: Region with borides. a) EDX maps, b) ACOM matching index map, c) phase+matching index map and d) IPF+matching index map for the carbide phase. All candidate phases were kept for the indexation by ACOM. e) EDX profile across the boride and carbide particles. f,g) acquired diffraction patterns on the boride particles and their comparison to the simulated patterns. 
phase reliability indeces $R$ indicate that they are distinguished without ambiguity. It must be acknowledged that the coexistence of several types of boride is a rather common observation in heat treated [25, directionally solidifed [19], and electron-beam melted microstructures [26]. By contrast, no such reports were available for microstructures fabricated by laser-powder bed fusion.

\section{5. $N i_{7} Z r_{2}$ compound}

In this work, a few particles have been identified as intermetallic compounds of monoclinic structure and stoichiometry $\mathrm{Ni}_{7} \mathrm{Zr}_{2}$. This phase is rarely observed in nickel-based superalloys, the only reports being from a weld line [17] and a directionally solidified omponent [27. The particle size is of the same order as the other types of particle. The other possible structure of nickel-zirconium listed in Table 2 , the $\mathrm{Ni}_{5} \mathrm{Zr}$ phase, has not been observed in this work, and it seems from the litterature that it never develops in nickel-based superalloys.

Figure 7 shows one region of carbon replica containing a particle of the $\mathrm{Ni}_{7} \mathrm{Zr}_{2}$ phase. Figure $7 \mathrm{a}$ show the peaks of nickel and zircoium associated with this particle. In a previous work [27, cobalt has also been associated with this phase, however, according to Figure 7, there does not seem to be strong evidence for its presence here. As for the other types of particles, the detection of a nickel-zirconium compound by EDX matches well the identification by ACOM of the $\mathrm{Ni}_{7} \mathrm{Zr}_{2}$ phase (Figure $\left.7 \mathrm{~b}-\mathrm{c}\right)$. Figure $7 \mathrm{f}$ shows that the $\mathrm{Ni}_{7} \mathrm{Zr}_{2}$ is identified without ambiguity. This is a remarkable achievement given the complexity of the crystallographic structure. Most likely, this phase is rarely observed due to its low fraction in the microstructure of conventionnal alloys. 


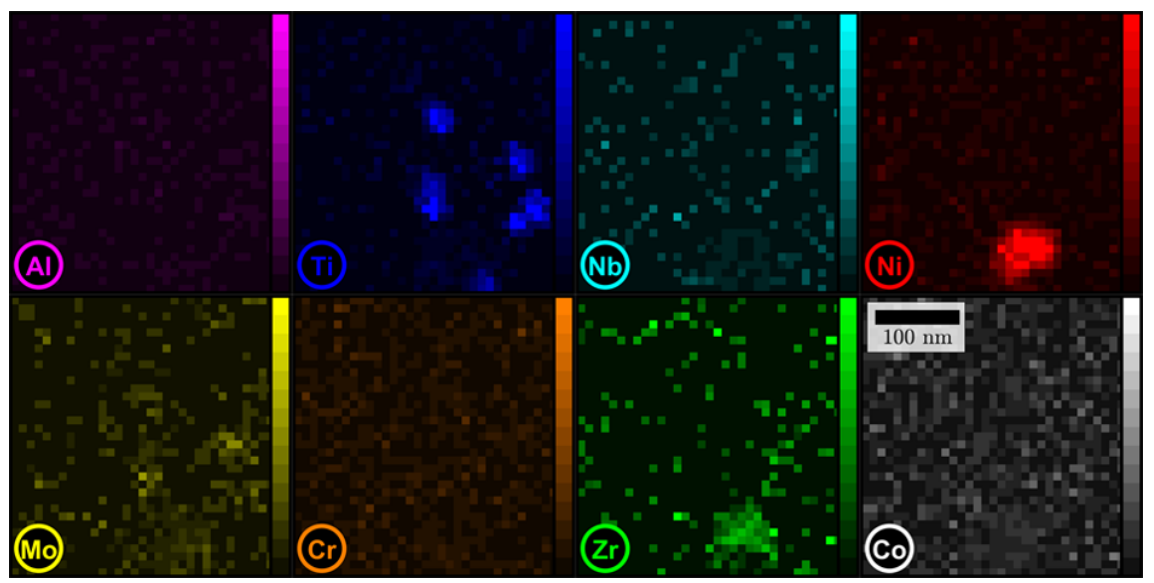

(a)

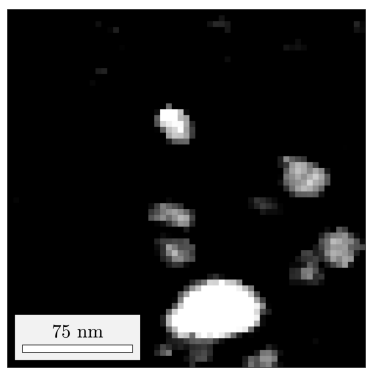

(b)

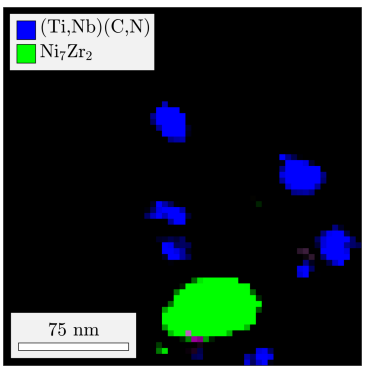

(c)

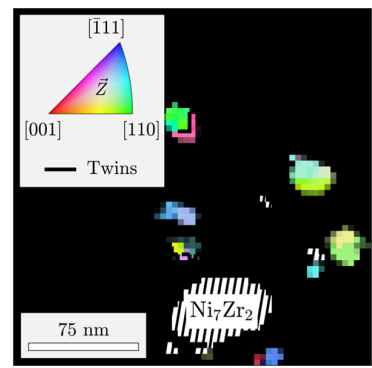

(d)

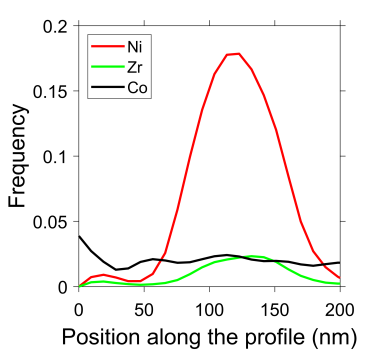

(e)

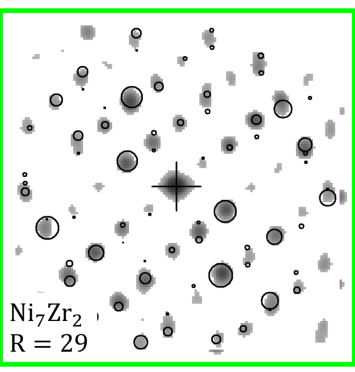

(f)

Figure 7: Region with $\mathrm{Ni}_{7} \mathrm{Zr}_{2}$ compound. a) EDX maps, b) ACOM matching index map, c) phase+matching index map and d) IPF+matching index map for the carbide phase. All candidate phases were kept for the indexation by ACOM. e) EDX profile across the $\mathrm{Ni}_{7} \mathrm{Zr}_{2}$ particle. f) a diffraction pattern acquired on the particle and its comparison to the simulated pattern. 


\section{Discussion}

\subsection{Precipitation sequence}

Knowing the nature of the second-phase particles, one can attempt to retrace the solidification path of the alloy and its subsequent precipitation sequence in the solid state. Figure 8 illustrates the solidification path by a Scheil's model simulation performed in Thermocalc. The model simulates the solute partitioning at the solid-liquid interface assuming no diffusion of elements in the solid and infinite diffusion in the liquid, and then predicts the precipitation sequence from knowledge of the composition at the interface. Only the phases identified experimentally and present in the databases were allowed to form for this simulation. Note that if all phases known by the Thermocalc database are allowed to precipitate, the $\gamma^{\prime}$ and $\eta$ phases are also predicted to form during solidification. This illustrates the need to inform Thermocalc simulations by thorough experimental characterizations.

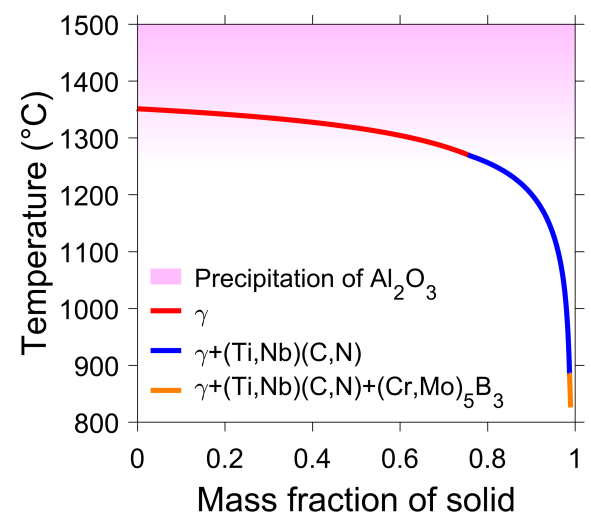

Figure 8: Solidification path as simulated in Thermocalc following Scheil's model. The thermodynamic database is TCNI9. The probable domain of precipitation of alumina has been added manually. In Thermocalc $\gamma$ corresponds to the DISFCCA1 \#1 phase, $(\mathrm{Ti}, \mathrm{Nb})(\mathrm{C}, \mathrm{N})$ to the DISFCCA1 \#2 phase, and $(\mathrm{Mo}, \mathrm{Cr})_{5} \mathrm{~B}_{3}$ to the $\mathrm{Cr}_{5} \mathrm{~B}_{3}$ phase.

Starting, in a schematic way, from a temperature way above the liquidus of the alloy (predicted to be $1350^{\circ} \mathrm{C}$ ), the first type of particle most likely to precipitate is alumina. Note that this phase is not predicted by the simulations 
as it is not included in the thermodynamic databases of nickel-based superalloys. Alumina having a melting point of $\sim 2050^{\circ}$ [28, it should in theory precipitate in the liquid before the $\gamma$ matrix phase. But it could also result from the decomposition of complex oxydes and hydoxydes present at the surface of raw powders [12, 13]. The $(\delta)$ structure of alumina found in this work is for example a decomposition product of hydroxydes [28]. In any case the pre-existence of alumina before other particle's phases is supported by the observation made in Figure 4 and Figure 5 that alumina particles act as nucleation sites for the subsequent precipitation of carbonitrides.

Past the liquidus of the $\gamma$ matrix phase, carbonitride particles start to precipitate around $1270^{\circ} \mathrm{C}$, corresponding to a solid fraction of $75 \%$. This prediction is in agreement with several differential thermal analysis performed in similar alloys [29, 30]. The carbonitride formation is from a thermodynamic point of view considered as eutectic since the $\gamma$ and $(\mathrm{Ti}, \mathrm{Nb})(\mathrm{C}, \mathrm{N})$ phases are predicted to increase in proportion to the decrease in liquid fraction. Pure nitrides may also be included in the simulations and are expected to form at a higher temperature than the liquidus, but this transformation corresponds more likely to a population of primary nitrides of several microns in size (see Appendix B than to the nano-particles of nitride visible for example in Figure 4 a.

In the terminal stages of solidification, boride particles are predicted to precipitate. This is notoriously caused by the rejection of boron in the residual liquid combined with the fact that this element is almost insoluble in the $\gamma$ phase matrix. As mentionned earlier, the coexistence of several boride phases in the same microstructure has been observed several times in nickel-based superalloys processed in various ways [26, 25, 19, which suggests that the stability of the different boride phases is almost equivalent. It is not surprising that the present simulation does not capture the coexistence of borides, since their precipitation is purely determined from energy levels set from the thermodynamic databases.

According to the thermodynamic simulations, the $\mathrm{Ni}_{7} \mathrm{Zr}_{2}$ compound phase does not precipitate during solidification but is present at equilibrium in the solid 
state below $850^{\circ} \mathrm{C}$. In their study of welds of Inconel samples, Ojo et al. [17] assert that this phase precipitates at the same time as $\gamma-\gamma^{\prime}$ eutectic formation. This scenario does not seem to be supported by the present results, where no eutectics are observed and the $\mathrm{Ni}_{7} \mathrm{Zr}_{2}$ phase is present as isolated particles.

\subsection{On the core-shell structure of carbonitrides}

Going beyond first order considerations of the precipitation sequence, it has been noticed in Figure 2 and Figure 4 that a number of carbonitrides exhibit a core-shell structure. In agreement with a previous work examining weld lines of nickel-based superalloys [23, the core is mostly constituted of titanium and nitrogen, while the shell contains more niobium and carbon. It has been stated in another work that the same case also occurs in directionally solidified components [30], althought a clear evidence was not provided.

One possible way of forming core-shell structures is to have large differences in diffusivity of the solute elements in the matrix combined with no diffusion in the precipitates. In this configuration, the precipitate cores contain the fastest elements while the slowest elements accumulate at the shell [31. Note, however, that this model was initially developed for solid-state transformations, while carbonitrides form in superalloys by eutectic transformation. In addition, the diffusion coefficients of titanium and niobium in nickel are of the same order of magnitude. Based on the coefficients given by Hagarther et al. [32, the diffusivity of niobium is even larger than that of titanium at all temperatures below the liquidus of the matrix. It is thus unlikely that core-shell structures of carbonitrides arise from differences of diffusivity between solute elements.

The second possible origin of core-shell structures is the minimization of the precipitate's free energy (assuming that the free energy of the matrix remains unchanged). A core-shell structure may develop to reduce (i) the interfacial tension at the precipitate matrix interface or (ii) the volume free energy due to the chemical activity of the solute elements. Following the Gibbs-Thomson description of the precipitate's free energy, the energy term related to the interfacial tension evolves in $r^{2}$, with $r$ the precipitate's radius, while the term of 
chemical activity is proportional to $r^{3}$ [33]. The fact that core-shell structures of carbonitrides are found for particles ranging from a fews tens of nanometers Figure 2 to a micron in size 23] suggests that the total free energy of carbonitrides is dominated by the volume contribution of chemical origin, and that the core-shell structure helps to minimize this contribution. Comparison to as-cast microstructures, where precipitates are expected to be even larger than in weld lines, would help to verify this hypothesis.

\subsection{On twinned carbonitrides}

One of the most remarkable observations made in this work is the twinned carbonitrides. The underlying mechanism leading to their formation remain unclear at the moment, but one may draw analogies with previous cases reported in the litterature. Indeed, Wang et. al 24] have observed twins in flower-shaped carbonitrides in a laser-remelted nickel-based superalloy, i.e. for processing conditions and, in particular, cooling rates, close to those implemented in laser powder bed fusion. In specific conditions, Cheng et al. 34 have also reported twinning of titanium nitrides prepared by chemical vapor deposition.

In these two cases taken from the litterature, twins were considered to form during the solidification or condensation of the carbonitride phase by a socalled mechanism of twin plane re-entrant edge growth. The formation of twins is thought to provide permanent sources of atomic steps facilitating the ledgedriven growth of the particle [33. The possibility of forming twins to accomodate the thermal strains is generally discarded based on energy considerations 34.

Although the details of this mechanism are not well understood, there is a general agreement that the formation of twins at solidification is modulated by the processing conditions, in particular cooling rates, and by the content of particular residual elements [34, 35, 36. This conception of the twin formation mechanism seems to agree with the fact that twinned carbonitrides have not been reported in nickel-based superalloys made by casting or welding. One may be tempted to think that if twins could develop during such processes, 
where due to the slow cooling rates the carbonitride size is of the order of the micron [17, 37, 38, 39], they would easily have been detected. Following this argument, twins within carbonitrides would result from the fast solidification conditions associated with laser powder bed fusion (i.e. with a cooling rate above $\left.\sim 10^{4} K \cdot s^{-1}\right)$.

\subsection{Consequences for processing}

As mentioned in the introduction, an ongoing challenge for the fabrication of nickel-based superalloy components by laser powder bed fusion is the formation of hot cracks during solidification [6, 7, 8]. Carter et al. [8] have shown that for components made by laser powder bed fusion, the process parameters offer little opportunity to control the hot cracking susceptibility of a given alloy (note that this is less true for parts made by electron beam melting [40]). The most common strategies to avoid hot cracking are thus of metallurgical character, namely (i) control of the nominal composition of the alloy, (ii) control of precipitation and (iii) grain refinement.

In this context, the precipitation of borides and zirconium intermetallic is a very important information as boron and zirconium are the elements most suspected to cause hot cracking [41. Although there is a current debate about second-order effects of these particles on hot cracking, their most direct effect is to remove the solute elements incriminated in hot cracking from the residual liquid film. Their precipitation is thus expected to decrease the hot cracking susceptibility of the alloys. At the same time, these elements cannot fully be removed due to their subsequent role on creep resistance. For a fixed content of these elements in the nominal composition, it is expected that the cracking suceptibility will decrease in proportion to the propensity of these particles to precipitate early in solidification and in extensive amount.

The low fraction of second-phase particles found in the as-built microstructure relative to observations made in casting and welding microstructures also suggest to adapt the subsequent solutionizing and ageing heat treatments. The several hours long solutionizing treatment, in particular, losses its purpose when 
the microstructure before heat treatment does not contain $\gamma^{\prime}$ phase precipitates. This treatment could be shortened significantly and confined to a recovery treatment. It is thus only natural that increasing attention should be paid to the role of heat treaments on the microstructure of components made by laser powder bed fusion [5, 42].

\section{Conclusion}

The as-built microstructure of nickel-based superalloys contains a large variety of nano-particles with complex internal structures. Those particles, located mostly in interdendritic regions and at grain boundaries, precipitate during solidification and cooling, in strong relation with microsegregations. In the alloy taken as example in this work, one finds by order of frequency carbonitrides, $(\delta)$ alumina, borides and the $\mathrm{Ni}_{7} \mathrm{Zr}_{2}$ compound. The experimental observations are remarkably well captured by Scheil's model predictions of the solidification path.

Several striking features were associated with specific particles, some of them being likely related to the laser powder-bed fusion process. Several particles were found to act as nucleation sites for others, in particular alumina for carbonitrides, and carbonitrides for borides. The isolated carbonitrides were also found to display occasionally core-shell structures of composition as well as internal twin boundaries. It is believed that these observations provide important insights on the fundamental mechanisms of precipitation taking place during fabrication. A better understanding of these aspects should help to tune the precipitation sequence and control the microsegregations in as-built microstructures.

The findings may of course vary as a function of the alloy composition and processing conditions, but the variety and the complexity of the precipitation state is expected to remain for any kind of nickel-based superalloys fabricated by laser powder-bed fusion. Finally, we stress out that the characteristics of the second-phase particles have been revealed in this work by a unique approach 
combining composition and crystallographic data. This rigorous methodology is relevant in multi-component alloys to discriminate the strongly similar candidate phases. The application of mapping techniques in the TEM seems to be a promising approach to achieve this goal for the fine microstructures of additive manufacturing.

\section{Acknowledgements}

This research has benefited from the characterization equipment of the Grenoble INP - CMTC platform supported by the Centre of Excellence of Multifunctional Architectured Materials "CEMAM" $\mathrm{n}^{\circ}$ ANR-10-LABX-44-01 funded by the Investments for the Future programme. Aubert et Duval is gratefully acknowledged for funding the post-doctoral contract of one of us (AD).

\section{References}

[1] A. Strondl, M. Palm, J. Gnauk, G. Frommeyer, Microstructure and mechanical properties of nickel based superalloy IN718 produced by rapid prototyping with electron beam melting (EBM), Materials Science and Technology 27 (5) (2011) 876-883, publisher: Taylor \& Francis_eprint: https://doi.org/10.1179/026708309X12468927349451. doi: 10.1179/026708309X12468927349451,

URL https://doi.org/10.1179/026708309X12468927349451

[2] J. Strößner, M. Terock, U. Glatzel, Mechanical and Microstructural Investigation of Nickel-Based Superalloy IN718 Manufactured by Selective Laser Melting (SLM), Advanced Engineering Materials 17 (8) (2015) 1099-1105. doi:10.1002/adem.201500158.

URL http://onlinelibrary.wiley.com/doi/abs/10.1002/adem. 201500158

[3] X. Wang, L. N. Carter, B. Pang, M. M. Attallah, M. H. Loretto, Microstructure and yield strength of SLM-fabricated CM247LC Ni-Superalloy, Acta 
Materialia 128 (2017) 87-95. doi:10.1016/j.actamat.2017.02.007.

URL

https://linkinghub.elsevier.com/retrieve/pii/

S1359645417300988

[4] Y.-L. Kuo, S. Horikawa, K. Kakehi, The effect of interdendritic delta phase on the mechanical properties of Alloy 718 built up by additive manufacturing, Materials \& Design 116 (2017) 411-418. doi:10.1016/j.matdes.2016.12.026

URL https://linkinghub.elsevier.com/retrieve/pii/ S026412751631543X

[5] O. M. D. M. Messé, R. Muñoz-Moreno, T. Illston, S. Baker, H. J. Stone, Metastable carbides and their impact on recrystallisation in IN738LC processed by selective laser melting, Additive Manufacturing 22 (2018) 394-404. doi:10.1016/j.addma.2018.05.030.

URL http://www.sciencedirect.com/science/article/pii/ S2214860417300556

[6] A. Hariharan, L. Lu, J. Risse, A. Kostka, B. Gault, E. A. Jägle, D. Raabe, Misorientation-dependent solute enrichment at interfaces and its contribution to defect formation mechanisms during laser additive manufacturing of superalloys, Physical Review Materials 3 (12) (2019)

123602. doi:10.1103/PhysRevMaterials.3.123602.

URL https://link.aps.org/doi/10.1103/PhysRevMaterials.3. 123602

[7] N. J. Harrison, I. Todd, K. Mumtaz, Reduction of micro-cracking in nickel superalloys processed by Selective Laser Melting: A fundamental alloy design approach, Acta Materialia 94 (2015) 59-68. doi:10.1016/j.actamat.2015.04.035.

URL http://www.sciencedirect.com/science/article/pii/ S1359645415002876

[8] L. N. Carter, X. Wang, N. Read, R. Khan, M. Aristizabal, K. Essa, M. M. 
Attallah, Process optimisation of selective laser melting using energy density model for nickel based superalloys, Materials Science and Technology 32 (7) (2016) 657-661. doi:10.1179/1743284715Y.0000000108

URL https://doi.org/10.1179/1743284715Y.0000000108

[9] H. Xiao, S. Li, W. Xiao, Y. Li, L. Cha, J. Mazumder, L. Song, Effects of laser modes on $\mathrm{Nb}$ segregation and Laves phase formation during laser additive manufacturing of nickel-based superalloy, Materials Letters 188 (2017) 260-262. doi:10.1016/j.matlet.2016.10.118.

URL https://linkinghub.elsevier.com/retrieve/pii/ S0167577X16317323

[10] E. A. Jägle, Z. Sheng, L. Wu, L. Lu, J. Risse, A. Weisheit, D. Raabe, Precipitation Reactions in Age-Hardenable Alloys During Laser Additive Manufacturing, JOM 68 (3) (2016) 943-949. doi:10.1007/s11837-015-1764-2 URL https://doi .org/10.1007/s11837-015-1764-2

[11] M. J. Donachie, S. J. Donachie, Superalloys: a technical guide, 2nd Edition, ASM, Materials Park, Ohio, 2008, oCLC: 705955133.

[12] H. Gruber, M. Henriksson, E. Hryha, L. Nyborg, Effect of Powder Recycling in Electron Beam Melting on the Surface Chemistry of Alloy 718 Powder, Metallurgical and Materials Transactions A 50 (9) (2019) 4410-4422. doi: 10.1007/s11661-019-05333-7

URL http://link.springer.com/10.1007/s11661-019-05333-7

[13] H. Yu, S. Hayashi, K. Kakehi, Y.-L. Kuo, Study of Formed Oxides in IN718 Alloy during the Fabrication by Selective Laser Melting and Electron Beam Melting, Metals 9 (1) (2019) 19, number: 1 Publisher: Multidisciplinary Digital Publishing Institute. doi:10.3390/met9010019.

URL https ://www.mdpi .com/2075-4701/9/1/19

[14] A. J. Goodfellow, E. I. Galindo-Nava, K. A. Christofidou, N. G. Jones, T. Martin, P. A. J. Bagot, C. D. Boyer, M. C. Hardy, H. J. Stone, Gamma 
Prime Precipitate Evolution During Aging of a Model Nickel-Based Superalloy, Metallurgical and Materials Transactions A 49 (3) (2018) 718-728. doi:10.1007/s11661-017-4336-y.

URL https://doi .org/10.1007/s11661-017-4336-y

[15] E. F. Rauch, M. Véron, Automated crystal orientation and phase mapping in TEM, Materials Characterization 98 (2014) 1-9. doi:10.1016/j.matchar.2014.08.010.

URL http://ww.sciencedirect.com/science/article/pii/ S1044580314002514

[16] R. C. Reed, The Superalloys: Fundamentals and Applications 390.

[17] O. A. Ojo, N. L. Richards, M. C. Chaturvedi, Microstructural study of weld fusion zone of TIG welded IN 738LC nickel-based superalloy, Scripta Materialia 51 (7) (2004) 683-688. doi:10.1016/j.scriptamat.2004.06.013.

URL http://www.sciencedirect.com/science/article/pii/ S1359646204003641

[18] X. Hu, Y. Zhu, X. Ma, Crystallographic account of nano-scaled intergrowth of M2B-type borides in nickel-based superalloys, Acta Materialia 68 (2014) 70-81. doi:10.1016/j.actamat.2014.01.002.

URL https://linkinghub.elsevier.com/retrieve/pii/ S1359645414000111

[19] S. Seo, I. Kim, J. Lee, C. Jo, H. Miyahara, K. Ogi, Eta Phase and Boride Formation in Directionally Solidified Ni-Base Superalloy IN792 + Hf. Metallurgical and Materials Transactions A 38 (4) (2007) 883-893. doi:10.1007/s11661-007-9090-0.

URL http://link.springer.com/10.1007/s11661-007-9090-0

[20] E. Smith, R. W. Guard, Investigation of the nickel-rich portion of the system Ni-Zr, JOM 9 (10) (1957) 1189-1190. doi:10.1007/BF03398286.

URL https://doi .org/10.1007/BF03398286 
[21] E. Husson, Y. Repelin, Structural studies of transition aluminas. Theta alumina, European Journal of Solid State Inorganic Chemistry 33 (11) (1996) 1223-1231.

[22] Y. Repelin, E. Husson, Etudes structurales d'alumines de transition. I-alumines gamma et delta, Materials Research Bulletin 25 (5) (1990) 611-621, publisher: Pergamon. doi:10.1016/0025-5408(90)90027-Y. URL http://www.sciencedirect.com/science/article/pii/ $002554089090027 \mathrm{Y}$

[23] C. C. Silva, H. C. d. Miranda, M. F. Motta, J. P. Farias, C. R. M. Afonso, A. J. Ramirez, New insight on the solidification path of an alloy 625 weld overlay, Journal of Materials Research and Technology 2 (3) (2013) 228-237. doi:10.1016/j.jmrt.2013.02.008

URL https://linkinghub.elsevier.com/retrieve/pii/ S2238785413000537

[24] H. Wang, J. Zhang, Y. Tang, Z. Hu, N. Yukawa, M. Morinaga, Y. Murata, Rapidly solidified MC carbide morphologies of a laser-glazed single-crystal nickel-base superalloy, Materials Science and Engineering: A 156 (1) (1992) 109-116. doi:10.1016/0921-5093(92)90421-V.

URL https://linkinghub.elsevier.com/retrieve/pii/ $092150939290421 \mathrm{~V}$

[25] H.-R. Zhang, O. Ojo, Cr-rich nanosize precipitates in a standard heattreated Inconel 738 superalloy, Philosophical Magazine 90 (6) (2010) 765-782. doi:10.1080/14786430903270643.

URL http://www.tandfonline.com/doi/abs/10.1080/ 14786430903270643

[26] E. Chauvet, P. Kontis, E. A. Jägle, B. Gault, D. Raabe, C. Tassin, J.-J. Blandin, R. Dendievel, B. Vayre, S. Abed, G. Martin, Hot cracking mechanism affecting a non-weldable Ni-based superalloy produced by selective electron Beam Melting, Acta Materialia 142 (2018) 82-94. 
doi:10.1016/j.actamat.2017.09.047.

URL https://linkinghub.elsevier.com/retrieve/pii/ S1359645417308133

[27] Y. Murata, N. Yukawa, Solid-state reaction for ZrC formation in a Zrdoped nickel-based superalloy, Scripta Metallurgica 20 (5) (1986) 693-696. URL http://inis.iaea.org/Search/search.aspx?orig_q=RN: 17081800

[28] P. S. Santos, H. S. Santos, S. P. Toledo, Standard transition aluminas. Electron microscopy studies, Materials Research 3 (4) (2000) 104-114, publisher: Materials Research. doi:10.1590/S1516-14392000000400003.

URL http://wWw.scielo.br/scielo.php?script=sci_abstract\&pid= S1516-14392000000400003\&lng=en\&nrm=iso\&tlng=en

[29] J. Zhang, R. F. Singer, Hot tearing of nickel-based superalloys during directional solidification, Acta Materialia 50 (7) (2002) 1869-1879. doi:10.1016/S1359-6454(02)00042-3

URL http://www.sciencedirect.com/science/article/pii/ S1359645402000423

[30] A. Formenti, A. Eliasson, A. Mitchell, H. Fredriksson, Solidification Sequence and Carbide Precipitation in Ni-Base Superalloys In718, In625 and In939, High Temperature Materials and Processes 24 (4) (2005) 239-258, publisher: De Gruyter Section: High Temperature Materials and Processes. doi:10.1515/HTMP.2005.24.4.239.

URL http://www.degruyter.com/view/journals/htmp/24/4/ article-p239.xml

[31] E. Clouet, L. Laé, T. Épicier, W. Lefebvre, M. Nastar, A. Deschamps, Complex precipitation pathways in multicomponent alloys, Nature Materials 5 (6) (2006) 482-488. doi:10.1038/nmat1652.

URL http://www .nature.com/articles/nmat1652 
[32] C. Z. Hargather, S.-L. Shang, Z.-K. Liu, A comprehensive first-principles study of solute elements in dilute Ni alloys: Diffusion coefficients and their implications to tailor creep rate, Acta Materialia 157 (2018) 126-141. doi:10.1016/j.actamat.2018.07.020.

URL http://www.sciencedirect.com/science/article/pii/ S1359645418305482

[33] D. A. Porter, K. E. Easterling, M. Sherif, Phase Transformations in Metals and Alloys (Revised Reprint), Taylor \& Francis Group, Bosa Roca, UNITED STATES, 2009.

[34] H. Cheng, M. Hon, Texture formation in titanium nitride films prepared by chemical vapor deposition, Journal of Applied Physics 79 (10) (1996) 8047-8053. doi:10.1063/1.362358

URL http://aip.scitation.org/doi/10.1063/1.362358

[35] S.-Z. Lu, A. Hellawell, Growth mechanisms of silicon in AlSi alloys Journal of Crystal Growth 73 (2) (1985) 316-328. doi:10.1016/0022-0248(85)90308-2.

URL https://linkinghub.elsevier.com/retrieve/pii/ 0022024885903082

[36] S.-Z. Lu, A. Hellawell, The mechanism of silicon modification in aluminumsilicon alloys: Impurity induced twinning, Metallurgical Transactions A 18 (10) (1987) 1721-1733. doi:10.1007/BF02646204.

URL http://link.springer.com/10.1007/BF02646204

[37] H.-E. Huang, C.-H. Koo, Effect of Zirconium on Microstructure and Mechanical Properties of Cast Fine-Grain CM 247 LC Superalloy, Materials Transactions 45 (2) (2004) 554-561. doi:10.2320/matertrans.45.554

[38] Y. Jinxia, Z. Qi, S. Xiaofeng, G. Hengrong, H. Zhuangqi, Morphological evolution of MC carbide in K465 superalloy, Journal of Materials Science 41 (19) (2006) 6476-6478. doi:10.1007/s10853-006-0684-5

URL https://doi .org/10.1007/s10853-006-0684-5 
[39] X. W. Li, L. Wang, J. S. Dong, L. H. Lou, Effect of Solidification Condition and Carbon Content on the Morphology of MC Carbide in Directionally Solidified Nickel-base Superalloys, Journal of Materials Science \& Technology 30 (12) (2014) 1296-1300. doi:10.1016/j.jmst.2014.06.010.

URL http://www.sciencedirect.com/science/article/pii/ S1005030214001121

[40] P. Kontis, E. Chauvet, Z. Peng, J. He, A. K. da Silva, D. Raabe, C. Tassin, J.-J. Blandin, S. Abed, R. Dendievel, B. Gault, G. Martin, Atomic-scale grain boundary engineering to overcome hot-cracking in additively-manufactured superalloys, Acta Materialia 177 (2019) 209-221. doi:10.1016/j.actamat.2019.07.041.

URL http://www.sciencedirect.com/science/article/pii/ S1359645419304896

[41] J. Grodzki, N. Hartmann, R. Rettig, E. Affeldt, R. F. Singer, Effect of B, Zr, and C on Hot Tearing of a Directionally Solidified Nickel-Based Superalloy, Metallurgical and Materials Transactions A 47 (6) (2016) 29142926. doi:10.1007/s11661-016-3416-8

URL https://doi .org/10.1007/s11661-016-3416-8

[42] R. Muñoz-Moreno, V. D. Divya, S. L. Driver, O. M. D. M. Messé, T. Illston, S. Baker, M. A. Carpenter, H. J. Stone, Effect of heat treatment on the microstructure, texture and elastic anisotropy of the nickel-based superalloy CM247LC processed by selective laser melting, Materials Science and Engineering: A 674 (2016) 529-539. doi:10.1016/j.msea.2016.06.075.

URL http://www.sciencedirect.com/science/article/pii/ S0921509316307432 


\section{Appendices}

\section{A. Detection of elements in carbonitrides using EELS}

To avoid artefacts coming from the measurement method, carbonitrides,pure carbides and pure nitrides must be distinguished directly from the electron energy loss spectra. Figure A.9 shows examples of spectra measured on particles containing and free from nitrogen. In Figure A.9 a, there is a clear peak of nitrogen signal above the background energy loss distribution. By comparision, in Figure A.9b, the signal is much lower, but not null.

\section{B. Example of primary titanium nitride}

Figure B.10 shows an example of primary titanium nitride. The size and angular shape are characteristic of this type of particle [11, which is known to precipitate above the liquidus temperature of the matrix phase. 

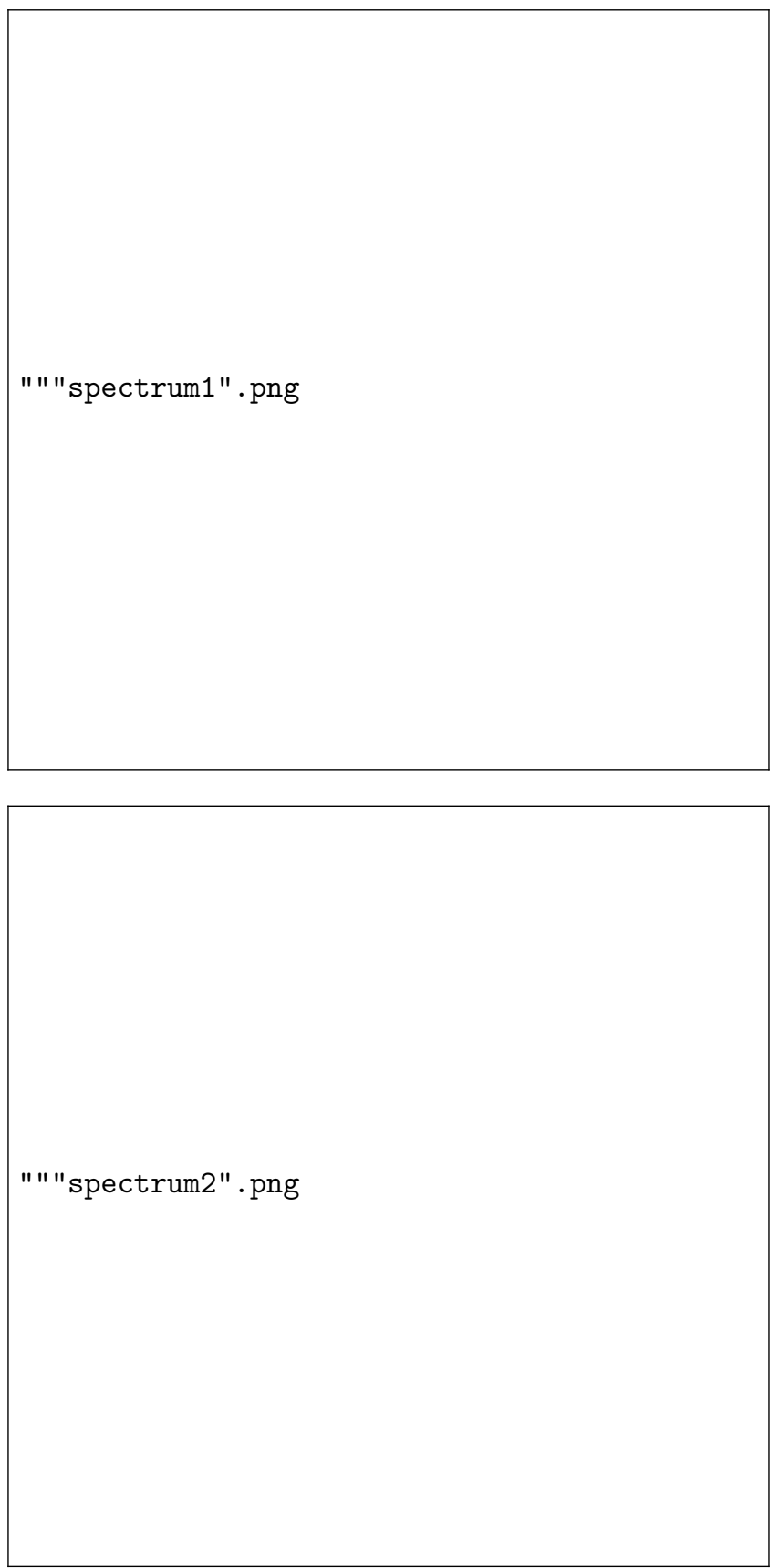

Figure A.9: Electron energy loss spectra around the energy level of nitrogen. a) for the carbonitride shown in Figure 2a. b) for the carbide shown in Figure 2. 


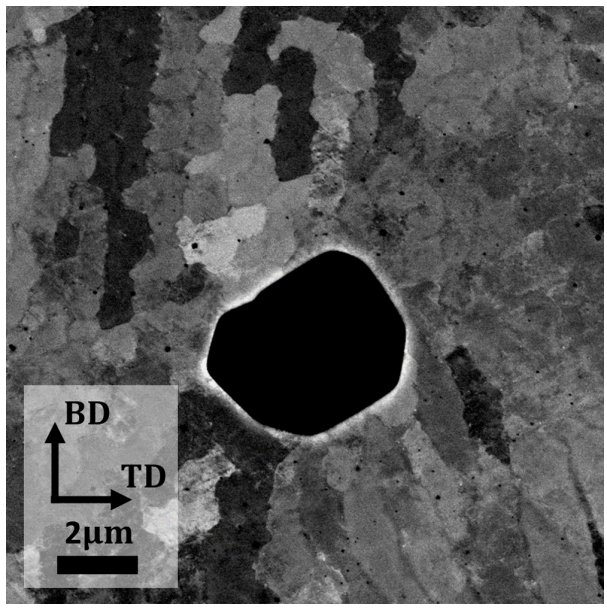

Figure B.10: Back-scattered electron micrograph of a primary titanium nitride. 